\title{
Increasing germination of 2 upland sedges, Carex inops ssp. inops and Carex tumulicola
}

\section{Kelly Broadlick and Jonathan D Bakker}

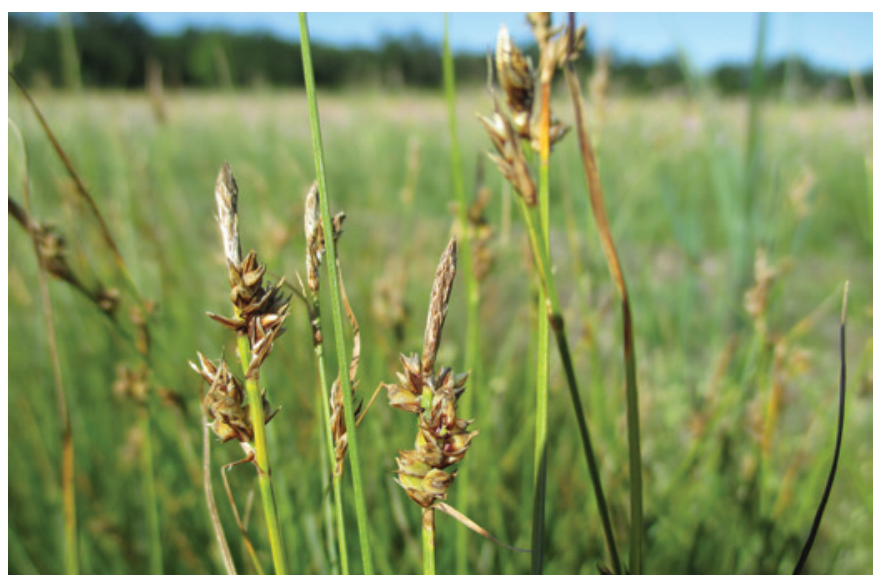

Seed head of Carex inops ssp. inops at the Violet Prairie Seed Farm, Tenino, Washington.

\section{ABSTRACT}

Propagation of native plants is generally more successful when plant scientists and managers have a broad understanding of the natural history of a species, including the conditions that seeds of that species require to germinate. We studied 2 sedges, Carex inops L.H. Bailey ssp. inops (long-stolon sedge [Cyperaceae]) and Carex tumulicola Mack. (splitawn sedge), that grow in upland prairies of western North America. We tested multiple combinations of stratification period and germination temperature to identify the best regime for increasing germination of each species. We also conducted smaller tests of smoke treatments and perigynia removal, which are additional ways to enhance germination. Based on our results, we recommend that $C$. tumulicola receive 2 mo of cold moist stratification and then be exposed to day/night temperatures of $15 / 8{ }^{\circ} \mathrm{C}\left(59 / 46^{\circ} \mathrm{F}\right)$ or $19 / 11^{\circ} \mathrm{C}\left(66 / 52^{\circ} \mathrm{F}\right)$ for $1 \mathrm{mo}$. We recommend that $C$. inops not receive cold moist stratification but instead be exposed to the same germination conditions for at least 2 mo. Germination patterns differ: C. tumulicola germinates rapidly and uniformly, whereas $C$. inops germinates nonuniformly over an extended period. Perigynia removal clearly

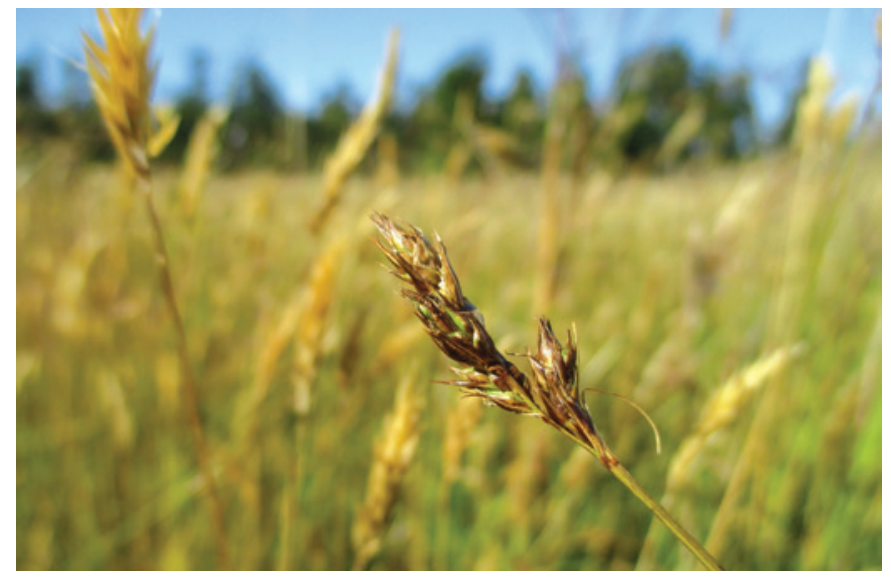

Seed head of Carex tumulicola at the Naas Preserve, Coupeville, Washington.

increases germination of $C$. inops. Smoke treatments had minimal effects on germination. Many of the germination requirements that we identified are consistent with the natural history of these species, such as differences in timing of seed maturation. By increasing the feasibility of propagating these species from seeds, our work enables genetically diverse populations of these species to be incorporated into restoration projects.

Broadlick K, Bakker JD. 2019. Increasing germination of 2 upland sedges, Carex inops ssp. inops and Carex tumulicola. Native Plants Journal 20(3):253-265.

\section{KEY WORDS}

seed dormancy, stratification, smoke water, perigynia, prairie, restoration, Cyperaceae

\section{NOMENCLATURE}

USDA NRCS (2018)

Photos by Kelly Broadlick

This open access article is distributed under the terms of the CC-BY-NC-ND license (http://creativecommons.org/licenses/ byncnd/4.0) and is freely available online at: http://npj. uwpress.org. 
$\mathrm{P}$ ropagation of native plants is generally more successful with a broad understanding of the natural history of individual species. We examined the germination requirements of 2 sedges, Carex inops L.H. Bailey ssp. inops (long-stolon sedge [Cyperaceae]) and Carex tumulicola Mack. (splitawn sedge), that occur in dry prairies of western North America. These species are a desirable component of prairie restorations, but previous propagation efforts have resulted in very poor $(<5 \%)$ germination (Krock and others 2016). Although these sedges also spread by rhizomes and can be propagated vegetatively, propagation from seed enhances genetic diversity in outplantings. In this study, we focused on dormancy release, germination temperature, smoke water, and perigynia removal.

Seed dormancy describes the physical, physiological, and (or) morphological conditions of a seed that prevent germination, even under ideal conditions of moisture and temperature (Baskin and Baskin 2014). The ability to delay germination until conditions are conducive is a common and important strategy for many native plants, especially those of temperate regions.

Sedges (Carex spp.) typically exhibit physiological dormancy at maturity (Baskin and Baskin 2014). Physiological dormancy can range from strict dormancy, in which seeds will not germinate under any conditions, to conditional dormancy, in which germination tends to happen at lower rates and only in optimum temperatures. Twenty wetland sedges investigated by Schutz (1997) and Kettenring and Galatowitsch (2007) all had conditionally dormant seeds at maturity. As with most physiologically dormant temperate species, dormancy was relieved by cold moist stratification for many of these sedges (Schutz 1997; Schutz and Milberg 1997; Schutz and Rave 1999; Kettenring and Galatowitsch 2007). More recently, Sobze and others (2019) reported that 9 wk of stratification increased germination for 2 of 5 upland sedges and 2 of 4 wetland sedges.

A reduction in dormancy following a period of afterripening (extended warm dry conditions) is common in species of dry habitats, including some sedges. For example, 4 to 8 wk of warm dry storage increased germination in 3 of 6 temperate wetland Carex species (Schutz 1997). In another study, after-ripening increased germination in 9 species while cold stratification increased germination in 4 species (Schutz 2000).

Germination percentage is typically highest for sedges exposed to warm temperatures (for example, $20-25^{\circ} \mathrm{C}\left[68-77^{\circ} \mathrm{F}\right]$; Schutz 2000). The ability to germinate in lower temperatures is often not gained until seeds are fully non-dormant. Some forest sedges have a lower optimum germination temperature, but in general, temperature requirements for Carex germination are usually quite high (Schutz and Rave 1999).

Carex inops ssp. inops and C. tumulicola occur on prairies that were traditionally managed by Native Americans through typically set in late summer and early fall to encourage the growth of prairie plants, many of which were important food crops. These fires reduced competition and released nutrients into the soil, providing opportunities for seed germination and establishment.

Indigenous communities around the world have known for centuries about the stimulatory effects of fire on plant communities, but the effects of smoke on germination were not noted in scientific literature until relatively recently. de Lange and Boucher (1990) found that the application of smoke increased the germination of Audouinia capitata, a threatened endemic South African shrub that had proven difficult to propagate from seed. Karrikins have since been identified as the compounds in smoke that stimulate germination (Flematti and others 2004; van Staden and others 2004) and also affect other aspects of plant growth (Meng and others 2016).

Karrikins are universally present in smoke, regardless of the vegetation type burned. They are also in the smoke produced by burning filter paper and in Liquid Smoke, a readily available flavoring product (Doherty and Cohn 2000; Flematti and others 2004). A common way of exposing seeds to smokederived compounds is to bubble the smoke through water and then apply the smoke water to the seeds. However, smoke water also contains compounds that inhibit germination; exposing seeds to undiluted smoke water often results in $0 \%$ germination and can even kill seeds (Doherty and Cohn 2000; van Staden and others 2004). Only when smoke water has been sufficiently diluted can the stimulating effects of karrikins occur, assuming that dormancy has already been relieved (Baskin and Baskin 2014). For example, germination responses of 37 smokesensitive species of Western Australia fluctuated seasonally due to changes in dormancy state (Roche and others 1998).

Another way to stimulate germination is to remove physical barriers to germination. Carex seeds are enclosed by the perigynium, a layer of tissue that varies in size, shape, thickness, and durability among species. The perigynium can dampen signals that stimulate germination and (or) physically restrict emergence of the seedling. Its removal improves germination in some species, including C. stipata (Hough-Snee and Cooper 2011), C. nebraskensis (Hoag and others 2001), and C. pensylvanica (McGinnis and Meyer 2011). Our focal species have very different perigynia: $C$. tumulicola has a thin perigynium that easily falls off of mature seeds, whereas $C$. inops has a thick perigynium that is wrapped tightly around the seed and has a swollen fleshy portion at the basal end.

In light of the above considerations, our objective was to evaluate the germination, dormancy, and viability of seed of C. inops and C. tumulicola. First, we tested 5 durations of cold, wet stratification ( $0-4 \mathrm{mo})$ and 3 post-stratification diurnal temperature regimes, and also made anecdotal observations about after-ripening. Second, we developed a protocol to test the effects of smoke water and Liquid Smoke on germination of 
non-dormant sedge seeds, building on the results of our dormancy release and germination temperature trial. Finally, since the perigynium does not fall off easily from C. inops, we tested whether removing it increased germination of this species.

\section{MATERIALS AND METHODS}

We tested 2 accessions of Carex inops ssp. inops and 1 accession of Carex tumulicola. All accessions were collected from western Washington State. One C. inops accession (Wild; 318 seeds/g; purity 98\%) was wild-collected from Tenalquot Prairie (Rainier, Washington) on 15 June 2015. The other C. inops accession (Farm; 362 seeds/g; purity 96\%) was harvested from plants at the Violet Prairie Seed Farm (Tenino, Washington) on 15 May 2015; these plants had been grown from seed that was wild-collected at several South Sound prairie sites. The C. tumulicola accession (681 seeds/g; purity 98\%) was wild-collected from Naas Prairie (Coupeville, Washington) on 13 September 2015. All seeds were stored at room temperature $\left(22^{\circ} \mathrm{C}\left[72^{\circ} \mathrm{F}\right]\right)$.

\section{Dormancy Release and Germination Temperature}

The first experiment aimed to identify the cold moist stratification period that would release dormancy and the optimal germination temperature for each species. Work began in September 2015. From each accession, 3200 seeds were imbibed in aerated deionized (DI) water for $24 \mathrm{~h}$, rinsed in a $10 \%$ concentrated bleach solution (1:9 bleach: DI water) for $1 \mathrm{~min}$, rinsed in DI water, and then blotted dry. Neither species has physical dormancy, so all seeds imbibed water readily.

For each accession, we counted out 16 groups of 200 seeds each (Table 1). We evenly divided each group of seeds into 4 lots, each of which was placed in a Petri dish $(100 \times 10 \mathrm{~mm}$, polystyrene, Carolina Biological Supply). Seeds were placed on

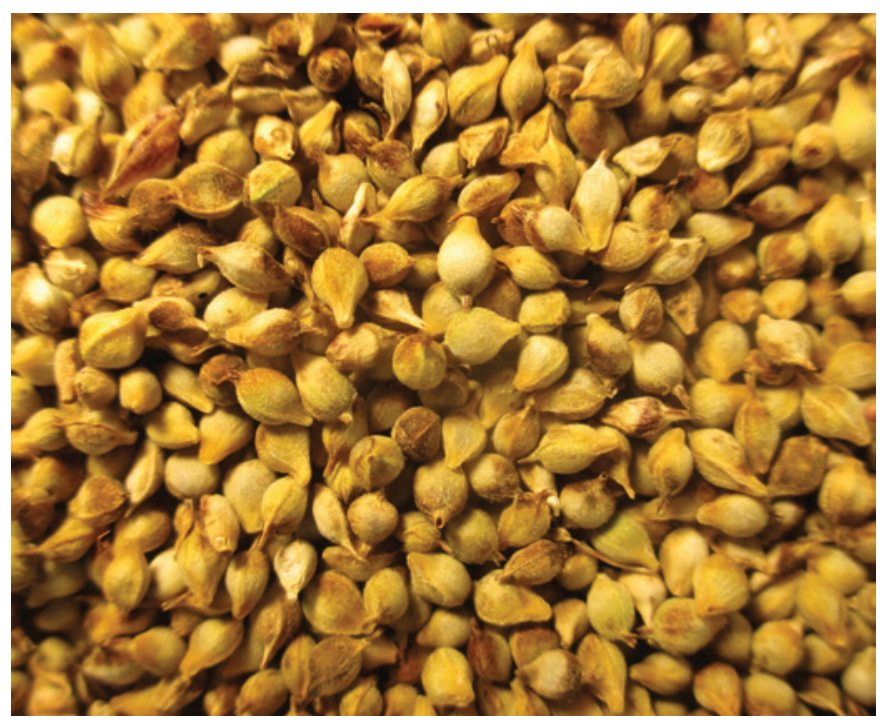

Cleaned seed of Carex inops ssp. inops.
2 sheets of filter paper $(9 \mathrm{~cm}$, qualitative, Carolina Biological Supply) moistened with DI water, covered with a lid, and placed in incubators. We used 4 incubators set to approximate the diurnal temperatures and light regime of typical western Washington seasons: winter, spring, intermediate, and summer. Winter conditions were $5^{\circ} \mathrm{C}\left(41^{\circ} \mathrm{F}\right)$ and light for $10 \mathrm{~h}$, then $2^{\circ} \mathrm{C}\left(36^{\circ} \mathrm{F}\right)$ and dark for $14 \mathrm{~h}$; these were also the conditions for cold moist stratification. Spring conditions were $15^{\circ} \mathrm{C}\left(59^{\circ} \mathrm{F}\right)$ and light for $12 \mathrm{~h}$ and then $8^{\circ} \mathrm{C}\left(46^{\circ} \mathrm{F}\right)$ and dark for $12 \mathrm{~h}$. Intermediate conditions were $19^{\circ} \mathrm{C}\left(66^{\circ} \mathrm{F}\right)$ and light for $12 \mathrm{~h}$ and then $11^{\circ} \mathrm{C}$ $\left(52^{\circ} \mathrm{F}\right)$ and dark for $12 \mathrm{~h}$; these conditions represent the shoulder seasons between spring and summer and between summer and fall. Summer conditions were $24^{\circ} \mathrm{C}\left(74^{\circ} \mathrm{F}\right)$ and light for $14 \mathrm{~h}$, and then $14^{\circ} \mathrm{C}\left(57^{\circ} \mathrm{F}\right)$ and dark for $10 \mathrm{~h}$.

Dishes were checked every 2 to $3 \mathrm{~d}$ for almost 3 mo (84 d). Germinants were tallied and removed, and DI water was added as necessary to keep the filter paper moist. Germination was defined as the emergence of both a radicle (embryonic root) and a coleoptile (embryonic leaf). Although no minimum length was specified, both had to be visible and identifiable, which usually occurred when they were at least $1 \mathrm{~mm}$ long. Seeds that had only 1 of the 2 structures, or for which they were too small to be distinguished, remained in the dish until they fully met the germination criteria or died.

\section{Stimulating Germination}

The second and third experiments evaluated additional ways to stimulate germination in non-dormant seeds. In the second experiment, we evaluated the effects of smoke-derived compounds on germination. Only 2 accessions, Farm C. inops and C. tumulicola, were evaluated in this trial; Wild C. inops was not included because the entire accession was used in the previous experiment. This experiment began in April 2016.

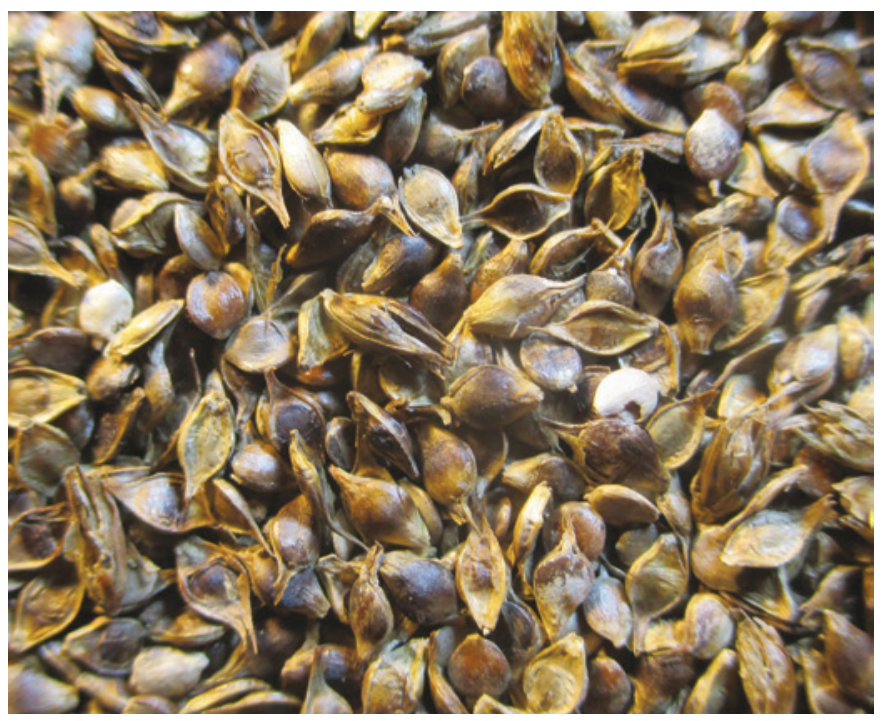

Cleaned seed of Carex tumulicola. 
Stratification periods ( $0-4 \mathrm{mo}$ ) and germination temperatures (spring, intermediate, summer, winter) experienced by each treatment during the dormancy release and germination temperature experiment.

\begin{tabular}{|c|c|c|c|c|c|c|c|}
\hline Treatment & Weeks 0-4 & Weeks 5-8 & Weeks 9-12 & Weeks 13-16 & Weeks $17-20$ & Weeks 21-24 & Weeks $25-28$ \\
\hline 0-SPR & Spring & & & & & & \\
\hline 0 -INT & Intermediate & & & & & & \\
\hline 1-SPR & Winter & Spring & & & & & \\
\hline $1-$ INT & Winter & Intermediate & & & & & \\
\hline 2-SPR & Winter & & Spring & & & & \\
\hline 2-INT & Winter & & Intermediate & & & & \\
\hline 2-SUM & Winter & & Summer & & & & \\
\hline 3-SPR & Winter & & & Spring & & & \\
\hline 4-INT & Winter & & & & Intermediate & & \\
\hline 4-SUM & Winter & & & & Summer & & \\
\hline WIN & Winter & & & & & & \\
\hline
\end{tabular}

Notes: Each treatment was applied to 200 seeds per accession. Winter treatment was included for visual comparison but was not analyzed statistically.

Smoke treatments were derived from 2 sources. The first, smoke water, was produced as described by Krock and others (2016) and de Lange and Boucher (1990). In September 2015, native prairie plant chaff was burned over Quercus garryana Douglas ex Hook. (Oregon white oak [Fagaceae]) coals and cooled smoke was pulled through DI water by vacuum suction.

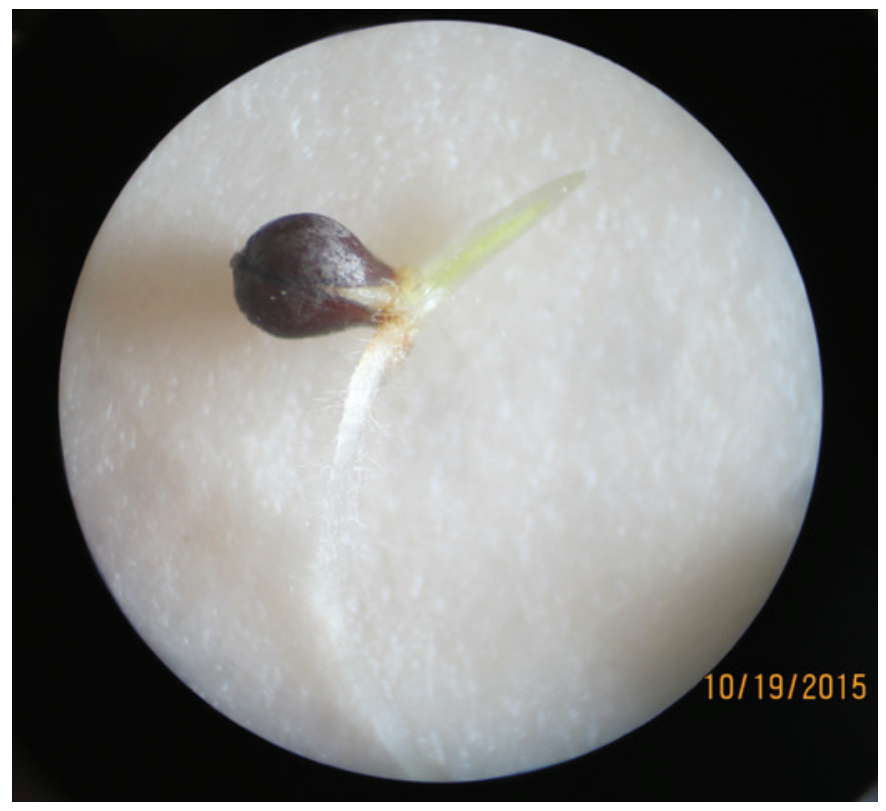

The second source, Liquid Smoke, is a commercial product (Wright's Hickory Liquid Smoke, B\&G Foods, Parsippany, New Jersey). Both smoke sources were stored frozen.

Three concentrations of each smoke treatment were evaluated: high $(0.01 \%)$, medium $(0.0001 \%)$, and low $(0.000001 \%)$. These concentrations were selected based on an initial trial

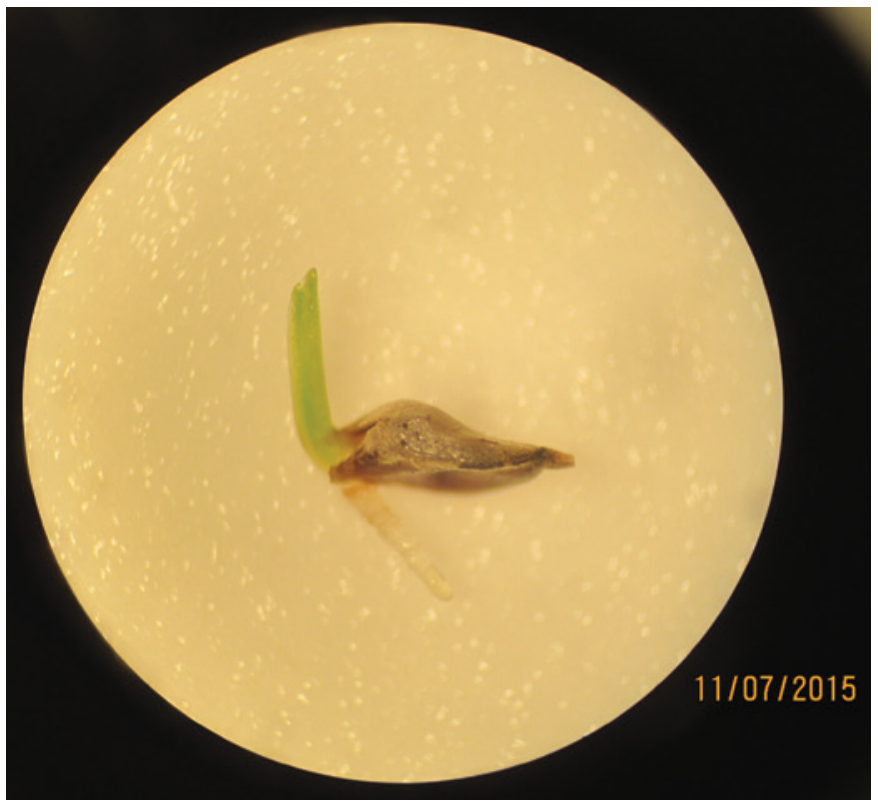

Newly germinating seedling of Carex tumulicola. 
in which each source was serially diluted and the effects of the dilutions on germination of lettuce seeds were measured (Broadlick 2016). A DI-water control was included for comparison.

Dry seeds from each accession were randomly separated into 7 groups of 200. Each group was placed in a piece of fine mesh screen and tied shut with a rubber band. From each smoke treatment dilution and from the DI-water control, $200 \mathrm{ml}$ were prepared and placed in open-topped glass jars at room temperature. Mesh bags were clipped to the inside of the jars to fully submerge seeds. Aquarium bubblers aerated the solutions.

After $56 \mathrm{~h}$ in the solutions, seeds were rinsed with tap water, swirled in a $10 \%$ concentrated bleach solution for $60 \mathrm{~s}$, and then rinsed again in tap water for $10 \mathrm{~s}$. Each group was then evenly divided into 4 lots, each of which was placed in a Petri dish. Seeds were placed on 2 pieces of filter paper and watered with DI water as described above. Germination regimes were chosen based on the results from the first experiment: $C$. inops was placed directly into intermediate conditions while $C$. $t u$ mulicola was placed in cold moist stratification for $8 \mathrm{wk}$ and then moved to intermediate conditions. Dishes were checked 3 times per week, germinants were tallied and removed, and additional DI water was added as needed.

The third experiment, perigynia removal, was conducted only on the Farm C. inops accession. The perigynium was removed from 200 dry seeds by rubbing them with 80 grit sandpaper in a $35 \mathrm{~mm}$ soil sieve. After perigynia removal, seeds were treated identically to the DI-water control of the smoke experiment.

\section{After-ripening}

Our smoke treatment and perigynia removal experiments were conducted more than 6 mo after the dormancy release and germination temperature experiment. During the interim, seeds were stored under warm $\left(22^{\circ} \mathrm{C}\left[71^{\circ} \mathrm{F}\right]\right)$, dry conditions in the laboratory. We realized later that we could compare germination patterns of seeds that received the same treatment after different lengths of storage, and thus make informal observations of whether after-ripening had occurred. We did so using the Farm C. inops and C. tumulicola accessions. Farm C. inops seeds that received no stratification and were exposed to intermediate conditions were used in the dormancy release and germination temperature experiment (initiated $19 \mathrm{wk}$ after seed collection) and the perigynia removal experiment (initiated 49 wk after seed collection). Carex tumulicola seeds that received 2 mo of stratification and then were exposed to intermediate conditions were used in both the dormancy release and germination temperature experiment (initiated $4 \mathrm{wk}$ after seed collection) and the smoke experiment (initiated 32 wk after seed collection). For each accession, we visually compared germination patterns to see if they varied with time since seed collection.

\section{Viability Testing}

At the end of each experiment, non-germinated seeds were tetrazolium (TZ) tested. Tetrazolium staining indicates whether a seed is physiologically active; seeds that do not stain are non-viable (Peters 2000). Some species, including some Carex spp., are difficult to test as seeds may not stain if in a state of deep dormancy (Vivrette and Meyr 2002). The recommended protocol (Peters 2000) led to poor staining, so we increased the staining period after consulting with Sabry Elias, a TZ testing expert at Oregon State University (Elias 2016). Specifically, we cut seeds longitudinally through the embryo and incubated them cut-face-down in $1 \% \mathrm{TZ}$ at 30 to $35^{\circ} \mathrm{C}(86-$ $95^{\circ} \mathrm{F}$ ) for $48 \mathrm{~h}$. One-half of each seed was tested. We evaluated viability using a dissecting microscope. Embryo staining, endosperm firmness, embryo size, and seed size were all taken into account in the assessment of viability. Staining in the aleurone layer was ignored. We placed difficult-to-classify seeds in a third category and later split them between the viable and non-viable categories.

\section{Analyses}

Germination counts and $\mathrm{TZ}$ results were compiled in a relational database and analyzed in $\mathrm{R}$ (version 3.5.1). We calculated 3 key variables: germination, the percentage of seeds that germinated; dormancy, the percentage of non-germinated seeds that were TZ-responsive; and viability, the percentage of seeds that either germinated or were TZ-responsive. Although these variables are expressed as percentages, analyses were based on counts of seeds that met or did not meet each criterion. Germination was our primary response variable and was calculated in all experiments and at multiple dates. We calculated cumulative germination over time. Germination patterns were explored by plotting cumulative germination percentages for each treatment group over time, from the date they were removed from stratification until 12 wk (84 d) later. Dormancy and viability, our secondary variables, were calculated only for the dormancy release and germination temperature experiment, at the end of the germination testing period.

We analyzed species separately since they germinated at very different rates. Statistical analyses of germination focused on patterns after $56 \mathrm{~d}$ for C. inops and after $28 \mathrm{~d}$ for C. tumulicola. These time periods were chosen to maximize differences in germination among treatments while minimizing the length of the germination period, since shorter germination periods are more useful for growers. Analyses used generalized linear models (GLMs) with a binomial distribution to assess the effects of stratification period ( 0 through 4 mo; treated as a factor), germination temperature (spring, intermediate, summer), and their interaction on the numbers of germinated and nongerminated seeds. Petri dishes were included as replicates in the analyses. For analysis of $C$. inops, we also included accession identity (Wild, Farm) in the model. The treatment that 
remained in winter conditions for the entire period was visually compared to the others but was not included in analyses as it was not part of our factorial experimental design. Treatments were compared on the basis of their statistical significance and the amount of deviance they accounted for. Significant treatments or interactions with more than 2 levels were followed by pairwise comparisons with Bonferroni corrections for multiple comparisons.

Dormancy and viability were analyzed using the same structure described above. For dormancy, the binomial response was the numbers of non-germinated seeds that were TZ-responsive and non-TZ-responsive. For viability, the binomial response was the numbers of live seeds (that is, sum of germinated and TZ-responsive seeds) and non-TZ-responsive seeds.
The effects of smoke water and Liquid Smoke were analyzed separately because there was no reason to expect the same concentrations of different sources to have the same effect. For each smoke source, we used a GLM with a binomial distribution to assess the effect of concentration (high, medium, low, none) on the numbers of germinated and non-germinated seeds. Analyses were conducted after 56 and $28 \mathrm{~d}$ of germination for C. inops and C. tumulicola, respectively.

The effect of perigynia removal on $C$. inops was assessed by comparing germination in the removal treatment with that in the DI-water control. This analysis used a GLM with a binomial distribution to assess perigynia removal (removed, intact) on the numbers of germinated and non-germinated seeds after $56 \mathrm{~d}$ of germination.
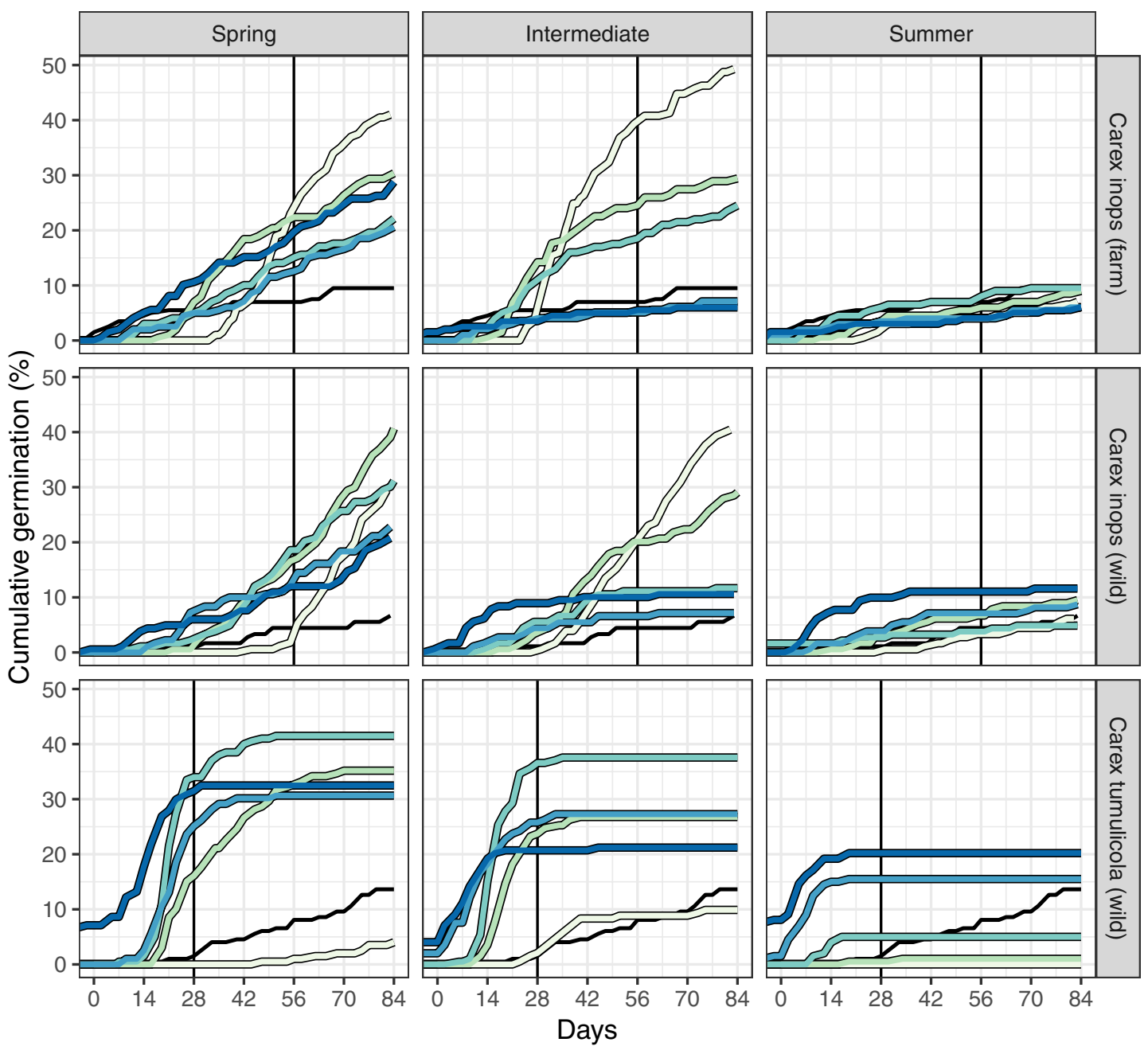

Months of Stratification
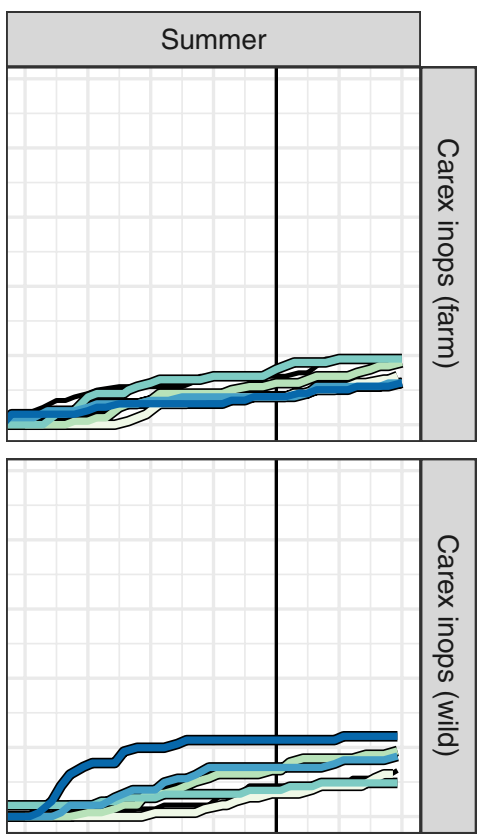

$2-3$

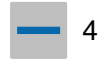

Figure 1. Cumulative germination patterns over $84 \mathrm{~d}(12 \mathrm{wk})$ for 2 accessions of Carex inops ssp. inops and 1 accession of C. tumulicola (rows) when placed in 3 different germination temperature regimes (columns) after being subject to different periods of stratification (colors). Data are averaged across 4 lots per treatment combination. Vertical lines indicate the dates at which germination was analyzed statistically (see Figure 2). The black germination pattern in each graph is from seeds that remained in winter conditions for another $12 \mathrm{wk}$ after 4 mo of stratification. 


\section{RESULTS}

\section{Dormancy Release and Germination Temperature: Germination}

Germination profiles varied strongly among germination temperatures, stratification periods, and species (Figure 1). For C. inops (both Farm and Wild), germination occurred gradually throughout the testing period, particularly under spring conditions or under intermediate conditions after no to little stratification (0-2 mo). For C. tumulicola, few seeds germinated without stratification and, for those that received stratification, most germination occurred during the first month after stratification.

All factors were statistically significant for $C$. inops germination after $56 \mathrm{~d}$, but the most important, in terms of deviance accounted for, were the main effect of germination temperature and the interaction between stratification period and germination temperature (Table 2; Figure 2). The main effect of germination temperature reflected higher germination under spring or intermediate than under summer conditions. The stratification period $\times$ germination temperature interaction occurred because stratification period had stronger effects for seeds that were subsequently exposed to intermediate conditions and had no effect on seeds exposed to summer conditions. The highest germination (39\%) occurred when seeds received no stratification and were exposed to intermediate conditions. Germination differed between accessions-it was higher for Farm- than for Wild-collected seed-though these differences were small compared to other terms. Interactions with accession were also significant but accounted for relatively little of the deviance, though some combinations differed considerably. For example, unstratified seeds exposed to spring conditions had 23\% germination for Farm-collected seed but only 2\% for Wild-collected seed.

All factors were statistically significant for C. tumulicola germination after $28 \mathrm{~d}$, but stratification period was by far the most important term (Table 2; Figure 2). Germination was much higher for seeds that received 2 or more mo of stratification; in numerous lots of unstratified seed, no germination occurred. The stratification period $\times$ germination temperature interaction was significant in part because seeds that received 2 mo of stratification were unlikely to germinate if exposed to summer conditions. The highest germination (36\%) occurred when seeds received 2 mo of stratification and were then exposed to intermediate conditions.

\section{Dormancy Release and Germination Temperature: Dormancy}

Dormancy levels of seeds that did not germinate were higher for C. inops than for C. tumulicola (34\% vs. 10\%). For C. inops, dormancy was strongly affected by stratification period and by the accession $\times$ stratification period interaction and was much less strongly affected by germination temperature (Table 2; Figure 3). Overall, dormancy was higher for seeds that experienced more stratification and for Wild- than Farm-collected seeds. The significant accession $\times$ stratification period interaction reflected a strong difference between accessions in the dormancy of unstratified seeds (Farm: 18\%; Wild: 45\%).

The effect of stratification period on C. tumulicola dormancy depended on the subsequent germination temperature (Table 2; Figure 3). These patterns were complex: Dormancy was highest for unstratified seeds placed under spring conditions, for seeds that received 3 mo of stratification and intermediate

\section{TABLE 2}

Statistical results of analysis of accession ( $A$; Carex inops only), stratification period (SP), and germination temperature (GT) on germination, dormancy, and viability of Carex inops ssp. inops and Carex tumulicola.

\begin{tabular}{|c|c|c|c|c|c|c|c|}
\hline \multirow[b]{2}{*}{ Species / Source } & \multirow[b]{2}{*}{ df } & \multicolumn{2}{|c|}{ Germination } & \multicolumn{2}{|c|}{ Dormancy } & \multicolumn{2}{|c|}{ Viability } \\
\hline & & Deviance & $P$ & Deviance & $P$ & Deviance & $P$ \\
\hline \multicolumn{8}{|c|}{ Carex inops ssp. inops } \\
\hline GT & 2 & 134.0 & $<0.001$ & 7.8 & 0.020 & 39.3 & $<0.001$ \\
\hline SP & 4 & 53.7 & $<0.001$ & 161.0 & $<0.001$ & 59.4 & $<0.001$ \\
\hline A:GT & 2 & 9.2 & 0.010 & 4.8 & 0.091 & 9.6 & 0.008 \\
\hline$A: G T: S P$ & 8 & 28.8 & $<0.001$ & 57.1 & $<0.001$ & 20.0 & 0.010 \\
\hline \multicolumn{8}{|l|}{ Carex tumulicola } \\
\hline GT & 2 & 93.3 & $<0.001$ & 2.0 & 0.374 & 108.9 & $<0.001$ \\
\hline SP & 4 & 250.6 & $<0.001$ & 30.2 & $<0.001$ & 57.0 & $<0.001$ \\
\hline GT:SP & 8 & 72.1 & $<0.001$ & 98.7 & $<0.001$ & 23.0 & 0.003 \\
\hline
\end{tabular}

Notes: Each species was analyzed separately. Germination is cumulative through 56 and $28 \mathrm{~d}$, respectively, for C. inops and C. tumulicola. Dormancy and viability were calculated after $84 \mathrm{~d}$ of germination. The treatment that remained in winter conditions was not included in these analyses. Statistically significant effects $(P \leq 0.05)$ are in bold. Data are in Figures $2-4$. 

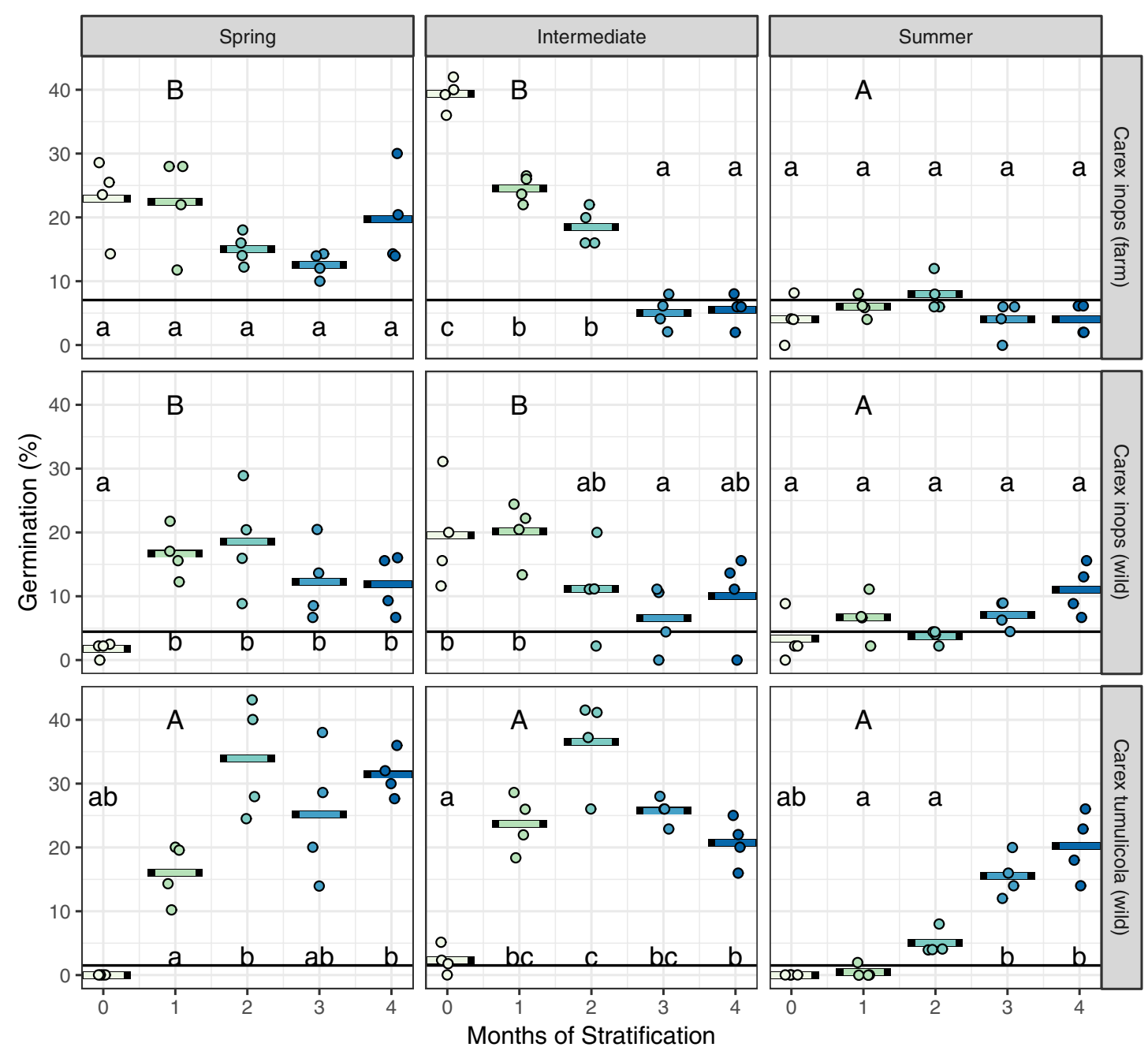

Figure 2. Germination (percentage of seeds that germinated) of 2 accessions of Carex inops ssp. inops and 1 accession of $C$. tumulicola (rows) when placed in 3 different germination temperature regimes (columns) after being subjected to different periods of stratification (colors). The black horizontal line within each row indicates the germination rate for seeds that remained in winter conditions. Data are cumulative through 56 and $28 \mathrm{~d}$ of germination for $C$. inops and C. tumulicola, respectively. Each point corresponds to a lot of 50 seeds (4 lots per treatment combination), and bars are mean values. Within each graph, stratification periods with the same lowercase letters are not statistically different from one another. Within each row, germination temperatures with the same capital letters are not statistically different from one another. Full statistical results are reported in Table 2.

conditions, and for seeds that received 2 mo of stratification and summer conditions.

\section{Dormancy Release and Germination Temperature: Viability}

Viability was higher for C. inops than for C. tumulicola (C. inops: 48\%; C. tumulicola: 32\%). For C. inops, the most important factors were stratification period and the accession $\times$ stratification period interaction (Table 2; Figure 4). Viability was lower in seeds that received 1 or 2 mo of stratification than in those subject to other stratification periods. The accession $x$ stratification period interaction was significant because viability was much less affected by stratification period for Farm- than for Wild-collected seeds. Seeds that were placed in summer conditions had lower viability than those that received spring or intermediate conditions.

Viability of C. tumulicola seed was most strongly affected by germination temperature: Seeds that received summer conditions had lower viability than those that received spring or intermediate conditions (Table 2; Figure 4). Viability was lower for seeds that received no stratification than for those that received a few months of stratification.

\section{Stimulating Germination}

Germination of $C$. inops was improved by low concentrations of smoke water, but not by Liquid Smoke (Figure 5). 

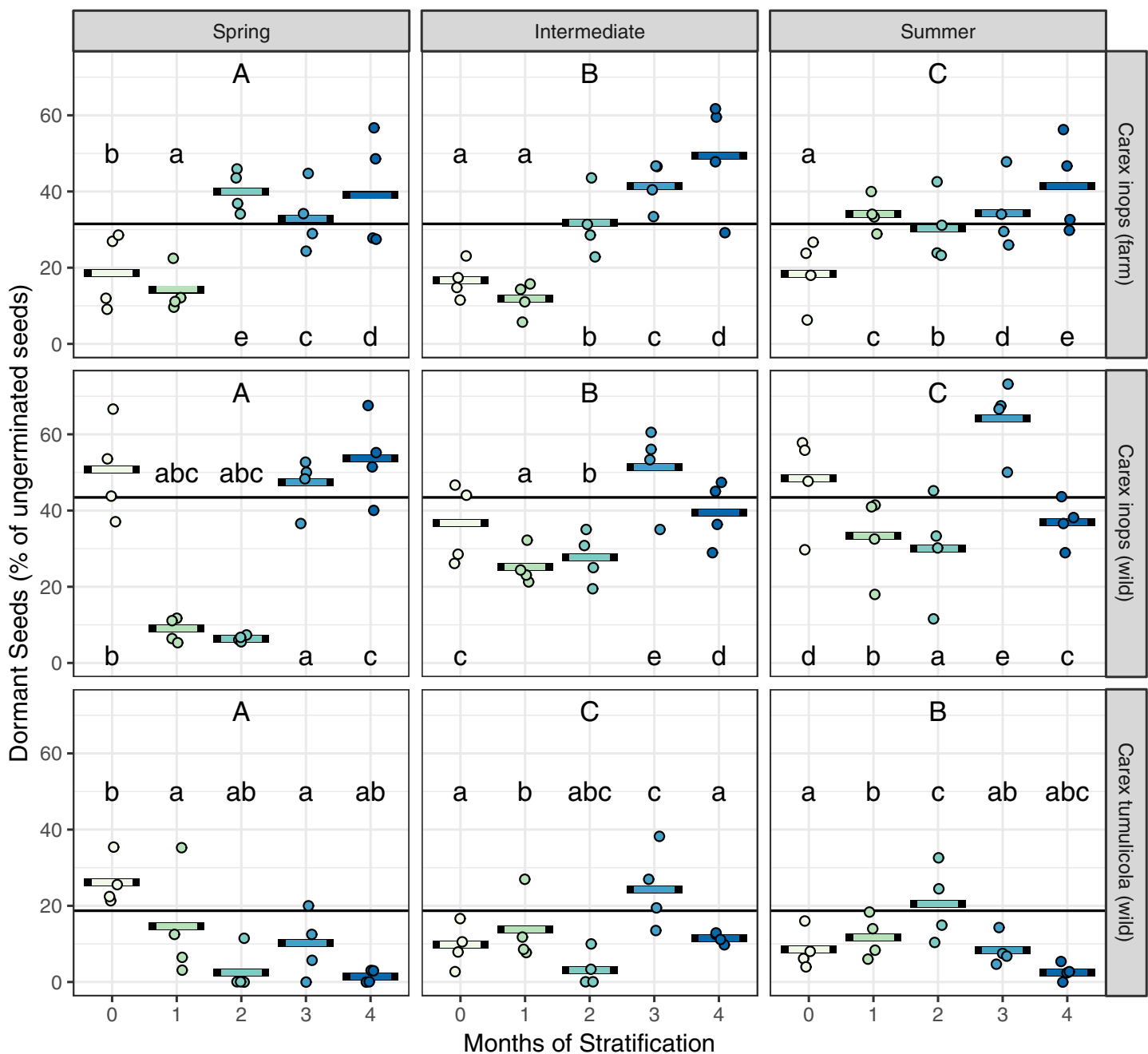

Figure 3. Dormancy (percentage of non-germinating seeds that responded to tetrazolium) of 2 accessions of Carex inops ssp. inops and 1 accession of $C$. tumulicola (rows) when placed in 3 different germination temperature regimes (columns) after being subjected to different periods of stratification (colors). Data were analyzed after $84 \mathrm{~d}$ of germination. Other details as in Figure 2. Full statistical results are reported in Table 2.

Perigynia removal more than doubled germination of C. inops seed $(P=0.0042)$, from $8 \%$ to $18 \%$. Germination of $C$. tumulicola tended to increase when exposed to medium or low concentrations of smoke water, or to medium concentrations of Liquid Smoke (Figure 5).

\section{After-ripening}

Comparisons of cumulative germination patterns (Figure 6) suggest that extended after-ripening delayed and reduced germination of $C$. inops. Perigynia removal increased the germination rate, though the total number of germinants remained lower than for the earlier experiment.

For C. tumulicola, after-ripening did not appear to affect the timing of germination but reduced it somewhat. Although the smoke water experiment assessed germination for only $28 \mathrm{~d}$, the earlier experiment strongly indicated that few additional germinants would be expected.

\section{DISCUSSION}

By varying the stratification period and germination temperature, we increased the germination of $C$. inops and C. tumulicola from $<5 \%$ (Krock and others 2016 ) to $\sim 40 \%$. This outcome is a measurable improvement over previous practices and means that these species can be more readily used by land managers. These species differ in germination requirements from many other Carex species. In particular, both species preferred spring or intermediate conditions for germination, with minimal germination under summer or winter conditions. Germination in winter is uncommon for many sedges from temperate regions, but germination in summer is fairly common (Schutz 2000). Most sedges are associated with wetlands, however, where summer may be the only time of year that the water is low enough to expose soil for germination. By contrast, the prairies where $C$. inops and C. tumulicola grow have 

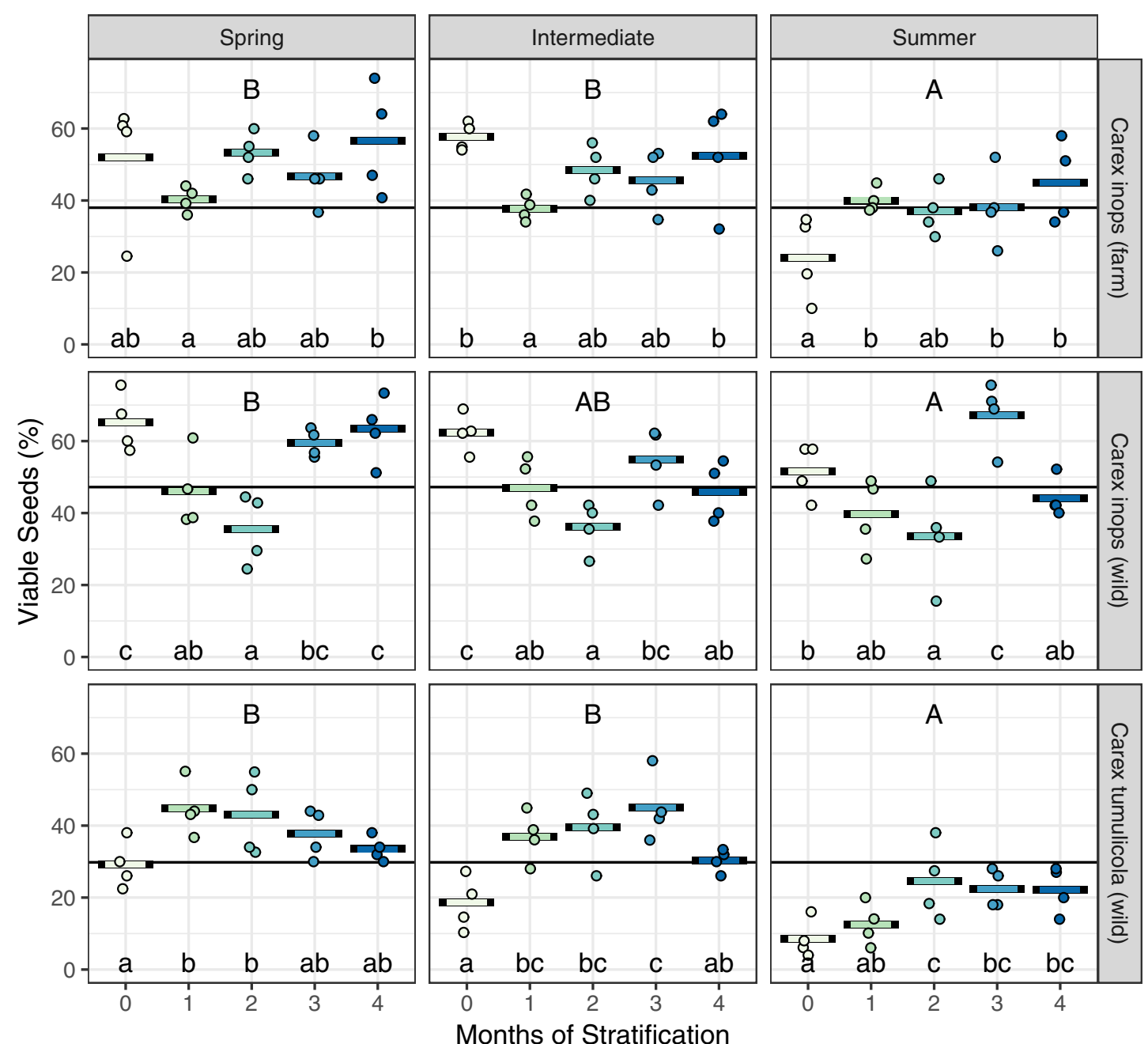

Figure 4. Viability (percentage of seeds that germinated or responded to tetrazolium) of 2 accessions of Carex inops ssp. inops and 1 accession of $C$. tumulicola (rows) when placed in 3 different germination temperature regimes (columns) after being subjected to different periods of stratification (colors). Data were analyzed after $84 \mathrm{~d}$ of germination. Other details as in Figure 2. Full statistical results are reported in Table 2.

well-drained soils and prolonged summer droughts, making summer a very inhospitable time for a germinating seedling.

Our results also demonstrate the necessity of evaluating species individually. These species are closely related and occur in the same ecological habitat yet have strikingly different stratification requirements. However, these differences are consistent with the ecological characteristics of the species. For example, their opposite responses to cold stratification correspond to differences in the timing of seed maturation. Each species' dormancy pattern appears to delay germination during the first unsuitable season following seed maturation and promote it during the next suitable season.

\section{Carex inops ssp. inops}

Carex inops seeds did not require stratification and germinated best under intermediate conditions. In the wild, seeds a long, dry summer before cooler temperatures and fall rains return, suggesting that germination would occur in the early fall once sufficient moisture is available. Germination would continue gradually until temperatures decrease enough to stimulate dormancy. Germination occurred non-uniformly, which would minimize the impacts of unfavorable events (dry weather, early freeze, for example) on population survival.

Carex inops is rhizomatous yet regularly produces small quantities of viable seed. The non-uniform germination patterns of this species and the delayed germination caused by the presence of the perigynia suggest that seeds may accumulate in the soil seedbank. For example, an average of 465 C. inops seeds $/ \mathrm{m}^{2}$ were in the soil of a young ( $<75$-year-old) forest that had encroached into a montane meadow in Oregon (Lang and Halpern 2007; Halpern and others 2015). Other work has shown that Carex seeds can survive over $130 \mathrm{y}$ in the soil (Schutz 2000). The seedbank can function as an insurance 
Figure 5. Effects of Liquid Smoke and smoke water (columns) on germination of Carex inops ssp. inops and C. tumulicola (rows). Data were analyzed after 56 and $28 \mathrm{~d}$ of germination for $C$. inops and C. tumulicola, respectively. Each point corresponds to a lot of 50 seeds (4 lots per treatment combination), and bars are mean values. The $P$ value of each test is reported in the associated graph and, where significant, lowercase letters identify statistical differences among concentrations.
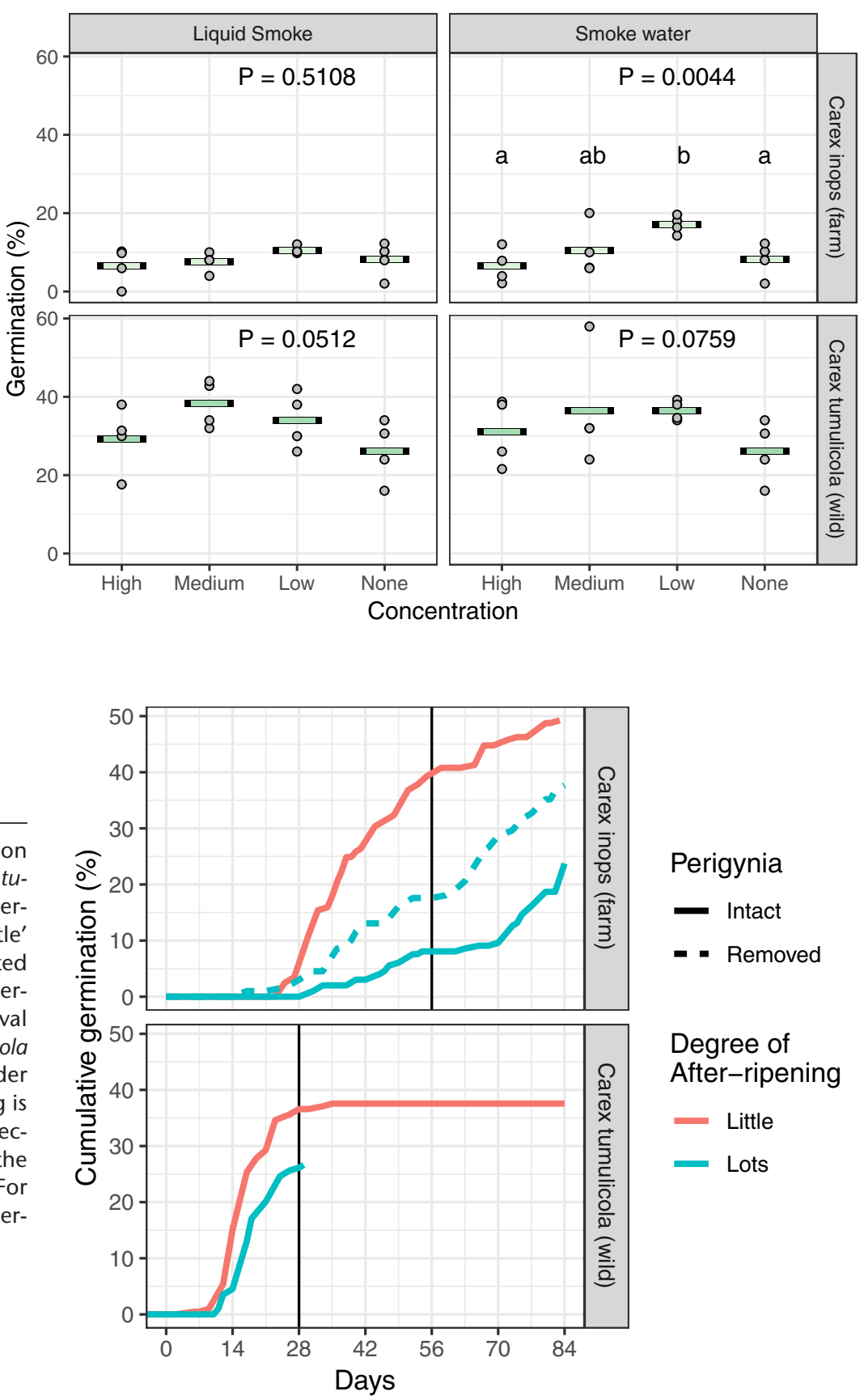

Figure 6. Anecdotal observations of after-ripening effects on cumulative germination of Carex inops ssp. inops and C. tumulicola. Carex inops seeds received no stratification and germinated under intermediate conditions; the line for 'Little' after-ripening is from the stratification experiment (initiated 19 wk after seed collection) and the lines for 'Lots' of afterripening are from the smoke water and perigynia removal experiments (49 wk after seed collection). Carex tumulicola seeds received 2 mo of stratification and germinated under intermediate conditions; the line for 'Little' after-ripening is from the stratification experiment ( $4 \mathrm{wk}$ after seed collection) while the line for 'Lots' of after-ripening is from the smoke water experiment (32 wk after seed collection). For reference, the vertical lines indicate the dates at which germination was analyzed statistically (see Figures 2 and 5).

policy against poor weather conditions and can be a means to capitalize on large disturbances. In the above-mentioned study in Oregon, C. inops established so abundantly once the trees were removed and a prescribed burn applied that it inhibited the establishment of other meadow plants.

Although relatively smaller than the differences among stratification periods and germination temperatures, we did detect differences among C. inops accessions. Farm-collected seeds germinated earlier and faster than did wild-collected seeds, and some differences were very pronounced, such as the difference in germination between unstratified seeds of the 2 accessions. These differences could reflect selective pressures in agricultural environments, but they are perhaps surprising as the seeds that we used were only one generation removed from wild-collected seed. Further research into variation among accessions and into the effects of agricultural practices on germination and dormancy is clearly required.

\section{Carex tumulicola}

Carex tumulicola seeds were dormant at the beginning of these experiments, and dormancy was relieved by exposure to cold moist stratification. Carex tumulicola seeds mature in September, so the fact that they require cold stratification suggests they naturally germinate in the spring. Our recommended 
germination regime, 2 mo of cold moist stratification followed by exposure to intermediate conditions, resulted in the highest level of germination, one of the highest levels of viability, and one of the lowest levels of dormancy. Longer stratification periods did not enhance germination and, since these conditions can provide opportunities for pathogens, we do not recommend their use. Interestingly, long-term exposure to winter conditions resulted in gradual, non-uniform germination similar to that for C. inops. Most combinations of stratification and exposure to spring or intermediate conditions resulted in higher germination, lower dormancy, and somewhat higher viability than were recorded for seeds kept in winter conditions.

Unlike C. inops, C. tumulicola demonstrated rapid and uniform germination under the optimal conditions we identified. Dormancy levels were also lower ( 20\%), implying that germination was fairly complete: Most seeds that could germinate at that point in time did so. These characteristics are not well suited to seedbanking, implying that $C$. tumulicola may not be as reliant on a seedbank.

Overall seed viability was lower for C. tumulicola than for C. inops. It is unclear whether non-viable seeds were dead or were unresponsive to tetrazolium because they were experiencing deep dormancy. If the latter, perhaps other germination conditions would stimulate these seeds to germinate. Many aspects of the germination environment could be adjusted, including daytime and nighttime temperatures, the diurnal temperature range, length of day and night, presence and intensity of light, and the addition of germination stimulators such as gibberellic acid.

\section{Implications for Plant Production}

Our results have several implications for plant production. Carex inops has non-uniform germination under most of the germination conditions that we identified. A longer germination period would result in even more germination, though the resulting germinants would also vary considerably in age and size, which could have implications for their subsequent performance. If plants are being grown as plugs, a sortable tray such as the Ray Leach Cone-tainer (Stuewe \& Sons Inc, Tangent, Oregon) would allow plants of different ages to be grouped and would alleviate some of the challenges of growing different-aged plants as a single crop. In comparison, C. tumulicola has rapid and uniform germination and thus is more convenient for propagators. Following our recommended germination regime should result in germination of most viable seeds, and a longer germination period would have minimal benefits for germination.

Incorporating perigynia removal into propagation protocols would measurably increase germination of $C$. inops, but doing so requires efficient and scalable perigynia removal methods. Of course, these methods must also not be so aggres- secondarily, we were not able to assess its effects on seeds that had received less after-ripening. We expect that perigynia removal would also enhance germination in these seeds, as we have no reason to expect after-ripening and perigynia removal to interact.

Our results provide limited support for the inclusion of smoke treatments. The Liquid Smoke treatment had a highly nonsignificant effect on germination of $C$. inops but tended to increase germination of $C$. tumulicola. It is unclear why the species differed in response to this treatment, but perhaps $C$. inops is more sensitive to the presence of other chemicals within $\mathrm{Li}$ quid Smoke. Most responses to smoke treatments were relatively small; much larger changes in germination were achieved by altering stratification period and germination temperature, or by removing the perigynia from $C$. inops seeds. Nonetheless, smoke treatments are inexpensive to apply so even small improvements in germination may be economically worthwhile. It is also possible that the smoke application method could be enhanced. For example, we applied smoke treatments before stratification and then moistened seeds with DI water during stratification. Since chemicals within smoke affect the germination of only non-dormant seeds, perhaps our approach reduced karrikin concentrations below active levels by the time dormancy was broken. Applying smoke treatments during or after stratification might be more effective.

Finally, we note that we stored seeds at room temperature since this was consistent with the natural conditions experienced by these species, but it is common practice to store orthodox seeds in cool dry conditions after collection. Our results therefore do not provide insight into the effects of storage under cool dry conditions. However, the higher germination rate in our study compared to studies that stored them under such conditions (Krock and others 2016) suggests that a limited amount of after-ripening during storage may have helped relieve dormancy for $C$. inops. Further research into this topic is warranted.

\section{CONCLUSIONS}

The germination protocols summarized here provide large improvements in propagation success for Carex inops ssp. inops and C. tumulicola. On the one hand, Carex tumulicola seeds require cold moist stratification but are otherwise straightforward to germinate. Carex inops, on the other hand, does not benefit from stratification but may prove more challenging to propagate because of its non-uniform and extended duration of germination. Further testing and application of these findings could further refine propagation protocols. For example, $C$. inops germination was much higher with a little after-ripening than with lots of after-ripening, and perigynia removal increased germination with lots of after-ripening, but we did not test perigynia removal with little after-ripening. 
Would this combination result in even more germination? By increasing the feasibility of propagating these species from seed, genetically diverse populations of these species can be incorporated into restoration projects.

\section{ACKNOWLEDGMENTS}

We thank the Center for Natural Lands Management (CNLM) and the Whidbey Camano Land Trust for providing seeds, and Carl Elliott, manager of Shotwell's Landing Nursery, for providing the smoke water. We thank Sierra Smith and Kern Ewing for comments on an earlier version of this work. This project was supported by grant F15AC00636 from the US Fish and Wildlife Service via subcontract WA-S-2015-052-0 from CNLM and by the David R M Scott Professorship.

\section{REFERENCES}

Baskin CC, Baskin JM. 2014. Seeds: ecology, biogeography, and evolution of dormancy and germination. 2nd ed. San Diego (CA): Academic Press.

Broadlick K. 2016. Determining the dormancy and germination requirements of two upland prairie sedges: Carex inops ssp. inops and Carex tumulicola. Seattle (WA): University of Washington.

de Lange JH, Boucher C. 1990. Autoecological studies on Audouinia capitata (Bruniaceae) I. Plant-derived smoke as a seed germination cue. South African Journal of Botany 56:700-703.

Doherty L, Cohn MA. 2000. Seed dormancy in red rice (Oryza sativa). $\mathrm{XI}$. Commercial Liquid Smoke elicits germination. Seed Science Research 10:415-421.

Dunwiddie PW, Bakker JD. 2011. The future of restoration and management of prairie-oak ecosystems in the Pacific Northwest. Northwest Science 85:83-92.

Elias S. 2016. Personal communication. Corvallis (OR): Oregon State University Seed Lab. Professor and Special Testing Supervisor.

Flematti GR, Ghisalberti EL, Dixon KW, Trengove RD. 2004. A compound from smoke that promotes seed germination. Science 305:977.

Halpern CB, Antos JA, McKenzie D, Olson A. 2015. Past tree influence and prescribed fire mediate biotic interactions and community reassembly in a grassland-restoration experiment. Journal of Applied Ecology 53:264-273.

Hoag JC, Dumroese RK, Sellers ME. 2001. Perigynium removal and cold, moist stratification improve germination of Carex nebraskensis (Nebraska sedge). Native Plants Journal 2:63-66.

Hough-Snee N, Cooper D. 2011. Perigynium removal improves seed germination in awl-fruit sedge (Carex stipata). Native Plants Journal 12:41-43.

Kettenring KM, Galatowitsch SM. 2007. Temperature requirements for dormancy break and seed germination vary greatly among 14 wetland Carex species. Aquatic Botany 87:209-220.

Krock S, Smith S, Elliott C, Kennedy A, Hamman ST. 2016. Using smoke-water and cold-moist stratification to improve germination of native prairie species. Native Plants Journal 17:19-27.

Lang NL, Halpern CB. 2007. The soil seed bank of a montane meadow: consequences of conifer encroachment and implications for restoration. Canadian Journal of Botany 85:557-569.
McGinnis EE, Meyer MH. 2011. After-ripening, stratification, and perigynia removal enhance Pennsylvania sedge germination. HortTechnology 21:187-192.

Meng Y, Shuai H, Luo X, Chen F, Zhou W, Yang W, Shu K. 2016. Karrikins: regulators involved in phytohormone signaling networks during seed germination and seedling development. Frontiers in Plant Science 7:2021.

Peters J. 2000. Tetrazolium testing handbook: contribution no. 29 to the Handbook on seed testing. Wichita (KS): Association of Official Seed Analysts.

Roche S, Dixon KW, Pate JS. 1998. For everything a season: smokeinduced germination and seedling recruitment in a western Australia Banksia woodland. Australian Journal of Ecology 23:111-120.

Schutz W. 1997. Primary dormancy and annual dormancy cycles in seeds of six temperate wetland sedges. Aquatic Botany 59:75-85.

Schutz W. 2000. Ecology of seed dormancy and germination in sedges (Carex). Perspectives in Plant Ecology, Evolution, and Systematics 3:67-89.

Schutz W, Milberg P. 1997. Seed dormancy in Carex canescans: regional differences and ecological consequences. Oikos 78:420-428.

Schutz W, Rave G. 1999. The effect of cold stratification and light on the seed germination of temperate sedges (Carex) from various habitats and implications for regenerative strategies. Plant Ecology 144:215-230.

Sobze J-M, Yücel ÇK, Smreciu A, Gould K. 2019. Effect of cold stratification on germination of 9 boreal sedges. Native Plants Journal 20:5-12.

[USDA NRCS] USDA Natural Resources Conservation Service. 2018. The PLANTS database. URL: http://plants.usda.gov/java/ (accessed 9 Oct 2018). Greensboro (NC): National Plant Data Team.

van Staden J, Jager AK, Light ME, Burger BV. 2004. Isolation of the major germination cue from plant-derived smoke. South African Journal of Botany 70:654-659.

Vivrette N, Meyr A. 2002. Testing native species with deep dormancy. Seed Technology 24:43-51.

\section{AUTHOR INFORMATION}

\section{Kelly Broadlick}

Native Plant Propagator

Fourth Corner Nurseries

5652 Sand Road

Bellingham, WA 98226

kelly@fourthcornernurseries.com

\section{Jonathan D Bakker}

Professor

School of Environmental and Forest Sciences

Box 354115, University of Washington

Seattle, WA 98195

jbakker@uw.edu 

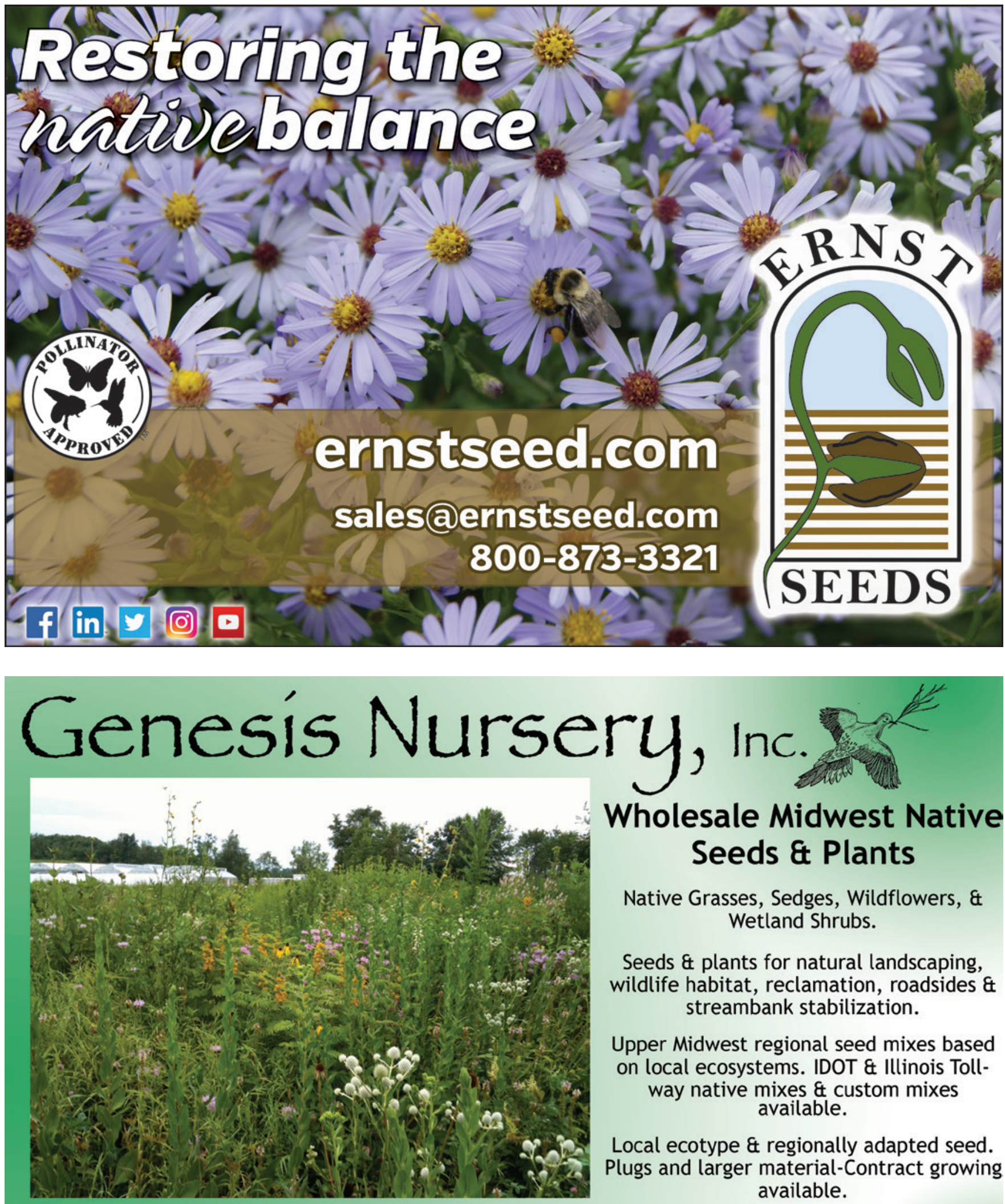

Send us your custom seed mix via fax or email. info@genesisnurseryinc.com

Toll Free: 877-817-5325 Fax: 815-438-2222 23200 Hurd Road Tampico, Il 61283

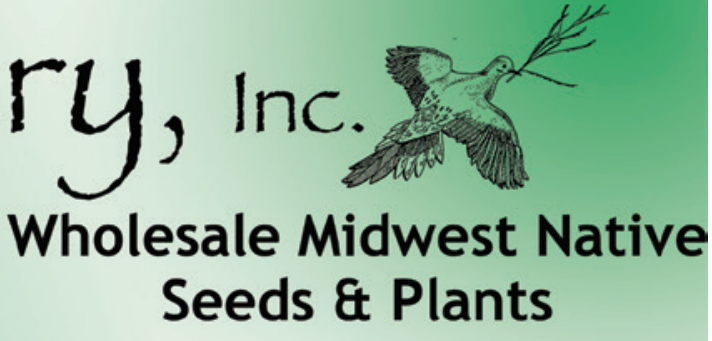

Native Grasses, Sedges, Wildflowers, \& Wetland Shrubs.

Seeds \& plants for natural landscaping, wildlife habitat, reclamation, roadsides \& streambank stabilization.

Upper Midwest regional seed mixes based on local ecosystems. IDOT \& Illinois Tollway native mixes \& custom mixes available.

Local ecotype \& regionally adapted seed. Plugs and larger material-Contract growing available.

Over 30 years experience in restoring Midwest landscapes.

www.genesisnurseryinc.com 